\title{
Agroecologia e juventude: um possível campo de investigação científica em ascensão
}

\author{
Agroecology and Youth: a possible field of scientific research on the rise \\ Laila Mayara Drebes ${ }^{1}$, José Geraldo Wizniewsky² \\ 'Mestranda no Programa de Pós-Graduação em Extensão Rural (PPGExR) da Universidade Federal de Santa Maria (UFSM). \\ ${ }^{2}$ Doutorado em Agroecología Sociología y Estudios Campesinos pela Universidade de Córdoba - UCO. Professor na Universidade Federal \\ de Santa Maria - UFSM.
}

\section{Resumo}

O estudo objetivou a identificação e a análise do conhecimento científico brasileiro produzido no campo de investigação da Agroecologia e Juventude. De abordagem quanti-qualitativa e de caráter exploratório, o estudo consistiu em uma pesquisa bibliográfica realizada nos periódicos Revista Brasileira de Agroecologia e Cadernos de Agroecologia entre os anos de 2006 e 2013. Os 25 trabalhos selecionados foram analisados e interpretados através do software Statistical Package for the Social Sciences (SPSS) e da metodologia de análise de conteúdo. Foi possível constatar que o campo de investigação da Agroecologia e Juventude é caracterizado por uma produção científica quantitativamente e qualitativamente restrita, centrada sobre as linhas temáticas formação e reprodução social. É, portanto, um campo de investigação emergente que necessita de mais estudos, com maior consistência teórica e empírica, sobre e para além das linhas temáticas já identificadas.

Palavras-chaves: Reprodução social. Formação. Meio rural. Pesquisa bibliográfica. Desenvolvimento sustentável.

\begin{abstract}
The study aimed to identify and analyze the brazilian scientific knowledge produced in research field of Agroecology and Youth. Approach of quantitative and qualitative and of exploratory nature, the study consisted of a literature search held in the periodic Revista Brasileira de Agroecologia and Cadernos de Agroecologia between the years 2006 and 2013. The 25 selected papers were analyzed and interpreted using the software Statistical Package for Social Sciences (SPSS) and methodology of content analysis. It was found that the research field of Agroecology and Youth is characterized by a scientific production quantitatively and qualitatively limited, focused on thematic lines formation and social reproduction. It is therefore a field of research on the rise it need more studies with greater theoretical and empirical consistency, over and beyond the thematic lines already identified.
\end{abstract}

Keywords: Social reproduction. Training; rural. Literature search. Sustainable development. 


\section{INTRODUÇÃO}

De origem tão antiga quanto a própria agricultura e a própria humanidade, respectivamente, a Agroecologia e a Juventude tardaram a serem percebidas enquanto categorias empíricas e demoraram ainda mais a serem compreendidas enquanto categorias de análise e interesse científico, sendo que seus surgimentos enquanto campos de investigação são recentes e ambos datados de meados do século XX.

Analisadas isoladamente, Agroecologia e Juventude atualmente consistem em campos de investigação praticamente consolidados (embora estejam em constante transformação e evolução), que se caracterizam pela relevância teórica e prática, pela crescente recorrência e produção científica, pela presença de autores e pesquisadores renomados e até mesmo por confusões conceituais provenientes da diversidade de abordagens possíveis. Além disso, esses campos também são caracterizados por algumas tentativas de aproximação e interligação entre os mesmos, que ao priorizarem determinados aspectos de cada um deles, possibilitam o entendimento de Agroecologia e Juventude de forma integrada como um campo de investigação novo, único e distinto.

Contudo, pouco se sabe sobre esse possível campo de investigação chamado Agroecologia e Juventude, se é que realmente constitui um campo de investigação. De modo geral, o que se percebe é que as aproximações e interligações entre Agroecologia e Juventude têm sido constituídas informalmente na esfera da extensão, sobretudo em espaços como encontros, seminários, jornadas, entre outros, promovidos, principalmente, por movimentos sociais e organizações não governamentais que acreditam que os jovens têm papel central nos processos de transição agroecológica e de desenvolvimento sustentável. Vale frisar a ocorrência de justaposições entre Agroecologia e Juventude até mesmo na esfera artística, tendo em vista a existência de uma canção ${ }^{1}$ que propõe que "é a juventude agroecológica que vai pintar o mundo todo de outra cor". Porém, o que dizer sobre as relações entre Agroecologia e Juventude tecidas formalmente na esfera científica?

Assim, inspirado na obra de Weisheimer (2005), o objetivo do presente estudo consiste em identificar e analisar o conhecimento científico que vem sendo produzido no Brasil sobre Agroecologia e Juventude com a finalidade de esboçar um panorama geral capaz de amparar o aprofundamento de algumas reflexões pontuais sobre este campo de investigação. Especificamente, o estudo se propõe a: realizar um levantamento quantitativo, tipológico, temporal, geográfico e institucional da produção científica referente a Agroecologia e Juventude; identificar e descrever as linhas temáticas mais recorrentes; e ponderar sobre as abordagens conceituais utilizadas tanto para Agroecologia quanto para Juventude. Feito isso, o estudo ainda tem a pretensão de refletir sobre os consensos e dissensos dessa produção científica, bem como sobre seus limites e potencialidades.

\section{METODOLOGIA}

O presente estudo foi conduzido por uma abordagem de pesquisa mista, utilizando os enfoques quantitativo e qualitativo de pesquisa de maneira intercalar e complementar. A pesdquisa é caracterizada por seu caráter exploratório, tendo como intuito "aventurar-se" pelo campo de investigação da Agroecologia e Juventude, "desbravando-o".

Para a realização do estudo foi utilizada a pesquisa bibliográfica. Essa modalidade de pesquisa é desenvolvida a partir das chamadas fontes bibliográficas, que são consideradas dados secundários e que compreendem uma diversidade de materiais que em sua elaboração já receberam tratamento analítico, como livros, teses, dissertações, artigos, entre outros (GIL, 2011). A principal vantagem da pesquisa bibliográfica consiste na possibilidade de elaboração de um estado da arte do tema estudado, favorecendo a sua apreciação a partir de pontos de vista inovadores e a formulação de conclusões originais (GIL, 2011).

A pesquisa bibliográfica foi realizada em abril de 2014 e seguiu alguns critérios e procedimentos padronizados a fim de garantir o rigor metodológico do estudo e de atingir o objetivo proposto. Assim, a mesma foi erigida sob a Associação Brasileira de Agroecologia (ABA), uma associação fundada no ano de 2004 e que reúne profissionais e estudantes das mais diversas áreas do conhecimento em prol da construção da Agroecologia enquanto enfoque científico, teórico, prático e metodológico capaz de

1 Canção denominada Juventude Agroecológica, autoria e interpretação da Banda Zafenate. 
apoiar a transição do processo de desenvolvimento de um modelo convencional para modelos sustentáveis (ABA, 2014). Diante do posicionamento da ABA como referência nacional para a Agroecologia, a presente pesquisa bibliográfica foi desenvolvida tomando por base os periódicos científicos publicados por essa Associação, sendo eles a Revista Brasileira de Agroecologia, que publica artigos científicos e também resumos de congressos e seminários apoiados pela ABA, e a Cadernos de Agroecologia, que publica apenas resumos de congressos e seminários.

Determinados os periódicos, estes foram acessados individualmente em seus endereços eletrônicos e em cada um deles se procedeu a busca por trabalhos que contivessem em seus títulos algum termo vinculado ao tema Juventude, desde a publicação dos primeiros volumes de ambos os periódicos, em 2006, até o ano de 2013. Os trabalhos previamente selecionados passaram por leituras flutuantes que permitiram excluir aqueles sem potencialidade de contribuir com o objetivo do estudo. Já os 25 trabalhos selecionados passaram por novas leituras, agora mais aprofundadas e exaustivas, a partir das quais foram construídas fichas bibliográficas, uma para cada trabalho, contendo as informações expressas de relevância para o estudo. A partir destas fichas bibliográficas, organizou-se a análise e interpretação dos resultados.

As informações abordadas quantitativamente foram analisadas e interpretadas com o auxílio do software Statistical Package for the Social Sciences (SPSS). Já as informações abordadas qualitativamente foram analisadas e interpretadas conforme a metodologia de análise de conteúdo.

\section{RESULTADOS E DISCUSSÃO}

\subsection{Agroecologia e Juventude: um retrato do campo de investigação}

A pesquisa bibliográfica resultou em um total de 25 trabalhos científicos sobre Agroecologia e Juventude publicados entre os anos de 2006 e 2013 nos periódicos da Associação Brasileira de Agroecologia (ABA). Esse dado demonstra que em termos de quantidade a produção científica sobre Agroecologia e Juventude não é muito expressiva, tendo em vista que a razão entre o número de trabalhos publicados e o período considerado é de apenas 3,1 trabalhos por ano.

Também se constatou que, da totalidade dos trabalhos em questão, apenas 1 (4\%) era artigo, sendo que os $24(96 \%)$ demais trabalhos eram resumos expandidos provenientes de eventos científicos que posteriormente foram publicados nos periódicos como anais. Além de apontar para a superficialidade de desenvolvimento desse campo de investigação, que apesar de seu potencial e de sua complexidade tem sido reprimido a trabalhos que tem em média 4,5 páginas, os dados também permitem refletir e questionar a respeito do rigor metodológico e da concisão dessa produção científica frente à consciência da maior flexibilidade dos eventos para a aceitação de trabalhos. É importante salientar ainda que todos estes trabalhos, sem exceções, foram fundamentados sobre a descrição de estudos de casos pontuais.

No que tange à distribuição temporal dos trabalhos sobre Agroecologia e Juventude (Figura 01), observa-se que a produção científica é instável e que picos de produção tendem a ocorrer de dois em

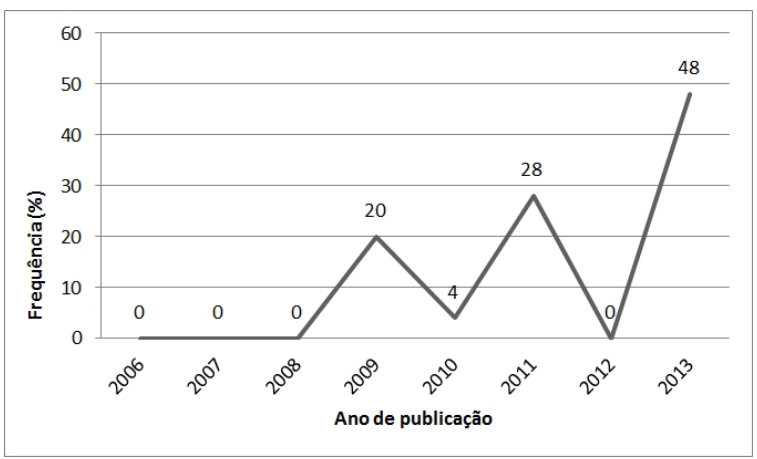

Figura 01 - Distribuição temporal das publicações relacionadas ao campo de investigação Agroecologia e Juventude nos periódicos da Associação Brasileira de Agroecologia (ABA) entre os anos de 2006 e 2013

Fonte: elaborado pelos autores 
dois anos em função da realização do Congresso Brasileiro de Agroecologia (CBA), o que explica as publicações vinculadas ao campo de investigação em questão nos anos de 2009, 2011 e 2013 e a baixíssima ou inexistente frequência de trabalhos nos anos intermediários ao CBA, no caso, 2010 e 2012.

Percebe-se também que no âmbito dos periódicos da ABA, 2009 é o primeiro ano a registrar a publicação de trabalhos sobre Agroecologia e Juventude, sendo precedido por três anos sem nenhum registro. Esse dado vai ao encontro dos demais resultados apresentados anteriormente, que apontam esse campo de investigação como recente e insipiente.

Com base na bibliografia apreciada também foi possível identificar a distribuição geográfica da referente produção científica em nível nacional (Figura 02). No âmbito dos periódicos da ABA, verifica-se a concentração dos estudos sobre Agroecologia e Juventude nas regiões Sul, Nordeste e Sudeste, que juntas contabilizam mais de $95 \%$ de toda a produção científica relacionada. Sabe-se que tais regiões são justamente as que congregam o maior número de instituições de ensino superior (ALVAREZ, 2013), o que pode explicar a baixa frequência de estudos nas regiões Centro-Oeste e Norte, sendo que, no que se refere a esta última região, não foi encontrado nenhum estudo vinculado.

Contudo, existem outras explicações plausíveis, como a importância e predominância da agricultura familiar nas regiões Nordeste, Sul e Sudeste (IBGE, 2009) e os incisivos avanços do agronegócio agropecuário e florestal nas regiões Centro-Oeste e Norte, respectivamente. Deve ser considerado, ainda, o fato de que as duas regiões de maior incidência de trabalhos vinculados ao campo de investigação da Agroecologia e Juventude coincidem com as sedes do CBA, congresso referido anteriormente, sendo que em 2009 e 2013 este foi realizado na região Sul (Curitiba/PR e Porto Alegre/RS, respectivamente) e em 2011 na região Nordeste (Fortaleza/CE).

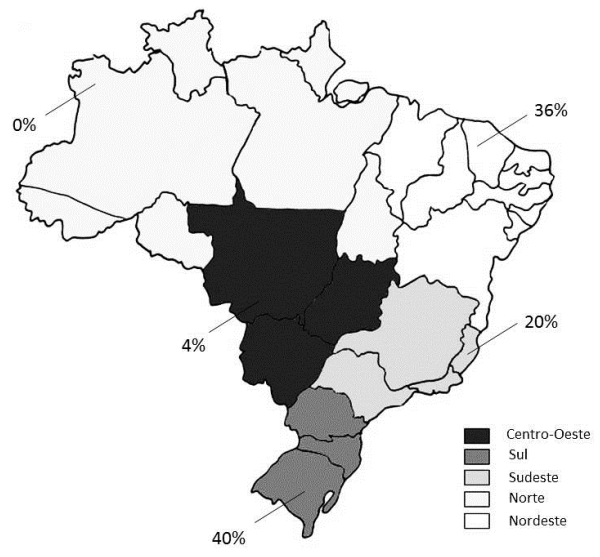

Figura 02 - Distribuição geográfica das publicações relacionadas ao campo de investigação Agroecologia e Juventude nos periódicos da Associação Brasileira de Agroecologia (ABA) entre os anos de 2006 e 2013

Fonte: elaborado pelos autores

Em termos institucionais, os trabalhos são oriundos de dezoito instituições diferentes, sendo que para esta análise deu-se preferência pela instituição do autor principal do trabalho (Figura 03). À primeira vista, as instituições que se destacam pelas publicações referentes a Agroecologia e Juventude são: a Universidade Federal da Paraíba (UFPB/PB), com 4 publicações (16\%), a Universidade Federal do Rio Grande do Sul (UFRGS/RS), com 2 publicações (8\%), a Universidade Federal de Santa Maria (UFSM/RS), com 2 publicações (8\%), a Universidade Tecnológica Federal do Paraná (UTFPR/RS), com 2 publicações (8\%) e a Universidade Federal de Campina Grande (UFCG/PB), também com 2 publicações (8\%). Juntas, essas instituições somam $48 \%$ da produção científica referente a Agroecologia e Juventude encontrada nos periódicos da ABA entre 2006 e 2013. Estes dados corroboram com outros dados já demonstrados anteriormente, pois manifestam que as instituições com maior número de publicações estão localizadas justamente em regiões com muitas instituições de ensino superior, que sediaram eventos científicos voltados à área nos últimos anos e que se destacam pela importância da agricultura familiar, sendo elas, sobretudo, as regiões Sul e Nordeste. 


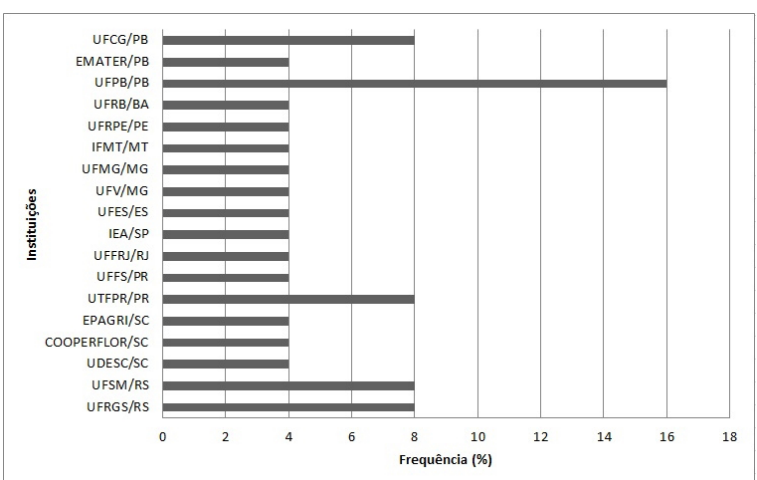

Figura 03 - Distribuição institucional das publicações relacionadas ao campo de investigação Agroecologia e Juventude nos periódicos da Associação Brasileira de Agroecologia (ABA) entre os anos de 2006 e 2013

Fonte: elaborado pelos autores

Ainda no que diz respeito à distribuição institucional, a Figura 03 permite conjecturar sobre os tipos de instituições das quais provém as contribuições científicas referentes a Agroecologia e Juventude. Percebe-se que, dos 25 trabalhos publicados, 22 (88\%) são oriundos de instituições de ensino superior e $3(12 \%)$ de instituições de assistência técnica e extensão rural, sendo estas instituições a Empresa de Pesquisa Agropecuária e Extensão Rural de Santa Catarina (EPAGRI/SC), a Empresa de Assistência Técnica e Extensão Rural da Paraíba (EMATER/PB) e a Cooperativa de Produtos da Agricultura Familiar e Economia Solidária (COOPERFLOR/SC). Apesar de pequena, a contribuição destas instituições de assistência técnica e extensão rural demonstra que a construção científica do campo de investigação da Agroecologia e Juventude têm extrapolado os limites das instituições de ensino superior.

\subsection{Estudos sobre Agroecologia e Juventude: identificando e descrevendo as linhas temáticas}

A partir da análise da bibliografia selecionada também foi possível identificar duas linhas temáticas gerais que tem norteado o desenvolvimento dos estudos do campo de investigação da Agroecologia e Juventude, sendo elas: 1) Agroecologia, juventude e reprodução social; e 2) Agroecologia, juventude e formação. A primeira linha temática englobou 8 (32\%) dos 25 trabalhos analisados e a segunda linha temática abarcou 17 (68\%) destes (Figura 04). As linhas temáticas foram definidas com base no tema central dos trabalhos, sendo que em alguns deles esta delimitação foi dificultada em virtude da sobreposição de ambas.

No que tange à linha temática mais proeminente, "Agroecologia, juventude e formação", esta se caracteriza pelo desenvolvimento da tese de que a formação agroecológica dos jovens é capaz de capacitá-los e transformá-los em protagonistas no processo de desenvolvimento sustentável como integrantes de redes de construção e disseminação do conhecimento agroecológico.

O que a bibliografia analisada demonstra é que essa formação agroecológica voltada para a

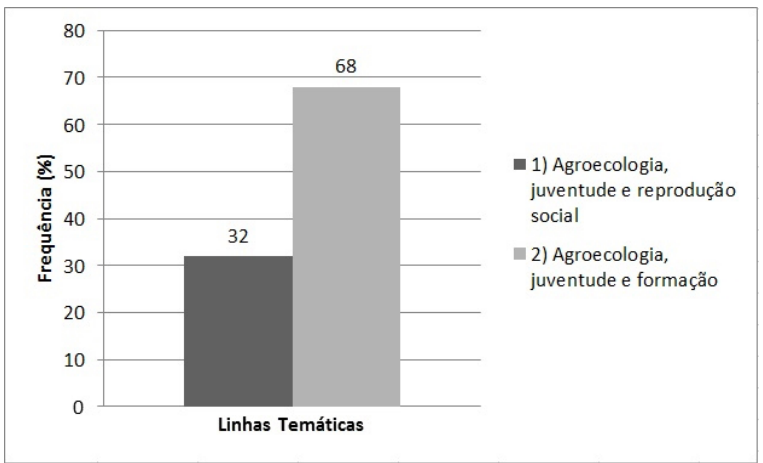

Figura 04 - Distribuição por linhas temáticas das publicações relacionadas ao campo de investigação Agroecologia e Juventude nos periódicos da Associação Brasileira de Agroecologia (ABA) entre os anos de 2006 e 2013

Fonte: elaborado pelos autores 
juventude é balizada pelos preceitos da chamada educação popular. Embora esta não seja citada de modo direto, está implicitamente presente no discurso de liberdade, autonomia e emancipação juvenil proferido nos trabalhos e também na escancarada utilização de metodologias alternativas, como é o caso da intervivência e da chamada pedagogia da alternância, que consiste em métodos educativos que não tratam apenas de estudar teoricamente a realidade, mas de vivenciá-la na prática (SANTANA et al.., 2009; SILVA et al., 2010; AMORIM; LOPES, 2011; MENDES et al., 2011; NUNES DA SILVA, 2011; OLIVEIRA et al., 2011; ARAÚJO et al., 2013).

Em conformidade com estas metodologias, são desenvolvidas atividades em múltiplos formatos voltadas para a formação agroecológica de jovens, como projetos, cursos, oficinas, coletivos, seminários, entre outros. Essas atividades se propõem a uma formação juvenil ampla e diversificada, perpassando por inúmeros assuntos, de pontuais a gerais, tais como: manejo ecológico de pragas de plantas alimentícias (SANTANA et al., 2009), uso e conservação de forrageiras nativas na alimentação animal (OLIVEIRA et al., 2011), apicultura e meliponicultura sustentável (GOMES et al., 2013), produção, plantio e condução de mudas (MENDES et al., 2011), sistemas agroflorestais (RAMOS, 2013), preservação ambiental (MENDES et al., 2011), reforma agrária (SILVA et al., 2010), artesanato (MENDES et al., 2011), noções básicas de administração (MENDES et al., 2011), entre outros. Além disso, vale destacar que por trás de tais iniciativas se encontram diferentes instituições que atuam como propulsoras da formação agroecológica da juventude, como instituições de ensino superior, organizações não-governamentais, movimentos sociais rurais e instituições de assistência técnica e extensão rural, para citar alguns exemplos.

Embora, de maneira geral, os trabalhos analisados evidenciem que a formação agroecológica tende a ser canalizada sobre jovens do meio rural, não é possível afirmar que a mesma seja exclusiva para estes. Alguns dos trabalhos considerados mostram experiências de formação agroecológica destinadas a públicos exclusivamente urbanos, ou ainda, a públicos mistos. A produção científica também permite refletir a respeito de certa prioridade da formação agroecológica para jovens marginalizados, sejam eles rurais ou urbanos, como foi possível notar em trabalhos que trataram de jovens assentados da reforma agrária, jovens quilombolas e jovens em processo de reabilitação (SILVA et al., 2010; GOMES et al., 2013).

Além de apontar como resultado desse processo formativo agroecológico a militância juvenil em prol do desenvolvimento sustentável, seja no meio rural ou no meio urbano, a produção científica analisada também defende que, especificamente no meio rural, essa formação agroecológica poderá influenciar na ampliação das possibilidades de permanência dos jovens, garantindo a reprodução social das propriedades de suas famílias através da concretização do processo sucessório, o que suscita a outra linha temática identificada.

A bibliografia referente à linha temática "Agroecologia, juventude e reprodução social" tem explorado a potencialidade da Agroecologia em garantir a perpetuação das propriedades rurais em curto e longo prazo. Os trabalhos considerados defendem que a introdução da Agroecologia nas propriedades rurais será capaz de garantir a satisfação econômica, social, política e ambiental de todos os membros das famílias rurais, inclusive dos jovens, favorecendo a sucessão familiar.

Os trabalhos analisados partem do pressuposto de que, agroecologicamente formados, os jovens rurais protagonizarão o processo de transição agroecológica, iniciando pela diversificação produtiva das propriedades rurais. Esta, por sua vez, desencadeará uma série de outros processos que tornarão a agroecologia capaz de influenciar as mais diversas estratégias de reprodução social das famílias rurais, culminando sobre as de sucessão.

Dentre os processos desencadeados pela diversificação produtiva agroecológica estão: a minimização da utilização de agrotóxicos e a consequente redução das intoxicações humanas e contaminações ambientais (TROIAN; DAL SOGLIO, 2013); a produção de culturas agrícolas destinadas não apenas para a comercialização, mas também para a subsistência, implicando em uma maior segurança e soberania alimentar (PASQUALOTTO et al., 2011; TROIAN; DAL SOGLIO, 2013); a centralidade do trabalho com o aumento do número de ocupações e o aumento da necessidade de mão-de-obra (OLIVEIRA; SCHNEIDER, 2009; PASQUALOTTO et al., 2013); a agregação de valor aos produtos (FERT NETO et al., 2013); a minimização dos riscos econômicos oriundos de produções especializadas (TROIAN; DAL SOGLIO, 2013); o acesso a novos mercados e novos nichos de mercado (TRICHES et al., 2013); entre outros. 
Diante de todas estas transformações, a bibliografia defende que a Agroecologia, enquanto campo de conhecimento científico, é capaz de revalorizar a profissão de agricultor (OLIVEIRA; SCHNEIDER, 2009) e de criar novos espaços de atuação para os jovens, inclusive para as moças, muitas vezes excluídas do processo produtivo (FERT NETO et al., 2013; PASQUALOTTO et al., 2013). É interessante constatar que nestes espaços criados os jovens não são vistos apenas como mão-de-obra passiva, submissos aos mandos e desmandos patriarcais, mas sim como protagonistas no processo de transição agroecológica. Esse protagonismo pode gerar, inclusive, o desenvolvimento de organizações sociais por parte desses jovens, que culmina em sua valorização identitária e profissional, enquanto jovens rurais e enquanto agricultores agroecologistas (REDIN, 2009, FERT NETO et al., 2013).

Em virtude de todas essas transformações, a linha temática "Agroecologia, juventude e reprodução social" aposta na tese de que a Agroecologia criará e recriará as mais diversas condições capazes de favorecer a permanência e a atração dos jovens para o meio rural e para as atividades agropecuárias, freando as migrações para o meio urbano e os processos de esvaziamento e masculinização do meio rural, como exposto no trabalho de Oliveira e Schneider (2009), que ao compararem propriedades rurais não-agroecológicas com propriedades agroecológicas, perceberam que nestas últimas a presença de pessoas, inclusive de jovens, é mais proeminente.

\subsection{Agroecologia e Juventude: um campo de investigação em busca de definições conceituais}

Dentre as diversas abordagens conceituais possíveis, para a elaboração do presente estudo partiu-se das definições de Agroecologia como paradigma científico e de Juventude como categoria socialmente construída como as mais adequadas para o entendimento de Agroecologia e Juventude enquanto campo de investigação científica.

Nesse sentido, entende-se a Agroecologia como uma ciência complexa e transdisciplinar balizada por um paradigma científico distinto daquele que orienta a ciência agronômica convencional, sendo que este paradigma é dito ecológico. Dessa maneira, a partir de um enfoque holístico e de uma abordagem sistêmica, tendo o agroecossistema como unidade de análise, acredita-se que o conhecimento construído por esta ciência será capaz de promover o processo de transição agroecológica e assim contribuir para que as sociedades possam redirecionar, de forma endógena e participativa, o curso alterado de sua coevolução social e ecológica rumo ao processo de desenvolvimento sustentável (ALTIERI, 1999; CASADO et al., 1999; GUZMÁN, 2001; GLIESSMAN, 2003).

Já a Juventude consiste em uma construção social que por influência do tempo e do espaço deve ser compreendida de forma específica, múltipla, variável e heterogênea. Isso significa que cada sociedade possui sua própria interpretação do que é ser jovem, baseada em representações sociais e imagens culturais formuladas por instituições adultas, como a família, a escola, a Igreja, o Estado, entre outras e também, pelos próprios indivíduos considerados jovens. Portanto, a Juventude é um conceito relativo (BOURDIEU, 1983; GROPPO, 2000; URTEAGA, 2011).

Contudo, ao analisar as publicações consideradas no presente estudo, foram raras aquelas que compartilharam destas mesmas concepções de Agroecologia e Juventude. Dos autores clássicos internacionais anteriormente citados, que propõem a Agroecologia como ciência e a Juventude como construção social, apenas Altieri e Bourdieu foram encontrados, de forma bastante breve e superficial, nas bibliografias analisadas. Em sua maioria, as bibliografias que trouxeram alguma problematização conceitual de Agroecologia e Juventude fizeram uso de definições consideradas simplistas, reducionistas e, até mesmo, arbitrárias.

No caso da Agroecologia, as publicações consideradas utilizaram o que Caporal (2009) denominou de conceitos vulgarizados, os quais concebem a Agroecologia como um simples modelo de agricultura que envolve a adoção de determinadas práticas ou tecnologias agrícolas ambientalmente mais adequadas. Dentre os inúmeros conceitos vulgarizados empregados, podemos destacar a Agroecologia como: uma forma de agricultura alternativa (SILVA et al., 2009); uma alternativa de produção de alimentos de melhor qualidade biológica e livres de agrotóxicos (SANTANA et al., 2009); uma agricultura mais limpa, socialmente justa e economicamente viável (PASQUALOTTO et al., 2011); uma forma de produção de alimentos livres de agroquímicos e de transgênicos, assim como a criação de animais que respeite parâmetros de seu bem-estar (TRICHES et al., 2013); práticas que garantam a sobrevivência no campo sem interferirem de forma agressiva no meio ambiente (PASQUALOTTO 
et al., 2013); entre outros. Para Caporal (2009, p.4) "essas interpretações expressam um enorme reducionismo do significado mais amplo do termo Agroecologia, mascarando sua potencialidade para apoiar processos de desenvolvimento mais sustentáveis".

Já no caso da Juventude, grande parte das publicações consideradas fizeram uso de critérios conceituais que Bourdieu (1983) considera capazes de manipular a ideia de Juventude, sobretudo critérios relacionados a idade biológica e a idade escolar, como os utilizados, respectivamente, por Mendes et al. (2011), que considerou como jovens aqueles que tivessem de 15 a 22 anos, e por Silva et al. (2009), que tomou por jovens os estudantes de um curso técnico profissionalizante de nível médio, entre outros trabalhos que utilizaram de critérios semelhantes. Na perspectiva de Bourdieu (1983), delimitações como estas não levam em consideração a complexidade das relações entre a esfera biológica e a esfera social e, portanto, geram compreensões arbitrárias do que é Juventude.

Além do uso de concepções errôneas, parte da produção científica também se caracterizou pela ausência de utilização de qualquer concepção de Agroecologia e de Juventude. Nesses trabalhos não foram encontradas nem sequer tentativas de problematização ou definição de Agroecologia e Juventude, tratando-as como categorias científicas pressupostas, dadas, autoexplicativas, capazes de dispensar quaisquer esforços conceituais.

\section{CONCLUSÕES}

Apesar da escassa e restrita produção relacionada, o presente estudo permite afirmar que o campo de investigação da Agroecologia e Juventude, ainda em fase de afirmação e expansão, é dotado de um grande e promissor potencial científico.

Basicamente, este campo de investigação tem se debruçado sobre duas linhas temáticas, que embora desenvolvidas de forma bastante superficial, possuem teses taxativas e consensuais no que tange ao papel estratégico dos jovens, sejam eles rurais ou urbanos, sobre os processos de transição agroecológica e desenvolvimento sustentável, seja através da formação ou da reprodução social. Apesar de fornecerem alguns indícios do que é e do que poderá vir a ser o campo de investigação da Agroecologia e Juventude, a análise da produção científica no interior de tais linhas temáticas não permite ir muito além.

O fato é que o campo de investigação da Agroecologia e Juventude, por ser contemporâneo, ainda não goza de estabilidade e credibilidade científica. Em razão das produções escassas, geralmente apresentadas no formato de resumos expandidos dedicados a relatos de experiências localizadas, as quais vêm sendo condicionadas temporalmente, geograficamente e institucionalmente pela ocorrência de eventos, esse campo de investigação ainda é permeado por inúmeras limitações, dentre as quais se destaca a falta de consistência teórica e empírica.

A falta de consistência teórica está relacionada ao fato de a produção científica desse campo de investigação ainda divergir sobre as abordagens de Agroecologia e Juventude e deixar a desejar em suas problematizações. A falta de consistência empírica se justifica pelo excessivo apreço às especificidades dos contextos locais explorados pelas publicações. Assim, fazem-se necessários mais estudos sobre Agroecologia e Juventude, teoricamente mais aprofundados e empiricamente mais amplos, capazes de permitir o compartilhamento de referenciais teóricos e a comparação de resultados. Dessa maneira, de certa forma, essas limitações se desdobram em oportunidades.

Para finalizar, espera-se e acredita-se que esse panorama geral do campo de investigação da Agroecologia e Juventude seja capaz de amparar e de incentivar o desenvolvimento quantitativo e qualitativo de estudos relacionados que, levando em consideração os apontamentos aqui realizados, possam representar um efetivo avanço para esse campo de investigação, sistematizando as linhas temáticas já identificadas e descobrindo novas.

\section{REFERÊNCIAS}

ALVAREZ, Ana Maria Torres. Panorama e diagnóstico da oferta e qualidade da educação superior brasileira. São Paulo: UNESCO/CNE, 2013. Disponível em: < file:///D:/Arquivos Cliente/Downloads/produto 1 senso 
educ superior.pdf $>$. Acesso em: 20 maio 2014.

ALTIERI, Miguel. Agroecologia: bases científicas para una agricultura sustentable. Montevideo: NordanComunidad, 1999.

AMORIM, Paulo César Gomes; LOPES, Leandro de Souza. Curso pré-vestibular popular de jovens do campo: tecendo sonhos. Cadernos de Agroecologia, v.6, n.2, p.1-3, dez. 2011. Disponível em: < http://www.aba-agroecologia.org.br/revistas/index.php/cad/article/view/11194>. Acesso em: 03 abr. 2014.

ARAUJO, Arabela Batista de; ARAUJO, Alexandre Eduardo; SILVA, Rayana Vanessa Alves. Juventude rural: percepções de uma jovem filha de agricultores familiares. Cadernos de Agroecologia, v.8, n.2, p.1-4, nov.2013. Disponível em: <http://www.aba-agroecologia.org.br/revistas/index.php/cad/article/view/15022>. Acesso em: 03 abr. 2014.

ASSOCIAÇÃO BRASILEIRA DE AGROECOLOGIA. Sobre a ABA-Agroecologia. 2014. Disponível em:

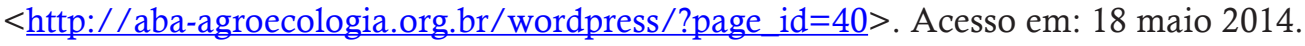

BOURDIEU, Pierre. A "juventude” é apenas uma palavra. In: BOURDIEU, Pierre. Questões de sociologia. Rio de Janeiro: Marco Zero, 1983. p. 112-121.

CAPORAL, Francisco Roberto. Agroecologia: uma nova ciência para apoiar a transição a agriculturas mais sustentáveis. Brasília, 2009. Disponível em: < www.territoriosdacidadania.gov.br/o/6235009>. Acesso em: 24 abr. 2014.

CASADO, Gloria Guzmán; MOLINA, Manuel González; GUZMÁN, Eduardo Sevilla. Bases teoricas de la agroecologia. IN: CASADO, Gloria Guzmán; MOLINA, Manuel González; GUZMÁN, Eduardo Sevilla (Orgs.). Introducción a la agroecologia como desarrollo rural sostenible. 535 p. Madrid/Barcelona/MéxicoDF: Ediciones Mundi-Prensa, 1999. p. $81-113$.

FERT NETO, João; SOUZA, Patrine; MADRUGA, Joseane; FERNANDES, Patrícia; WERTER, Silvia Danieli. Práticas agroecológicas, gênero e reprodução social da ruralidade no Planalto Sul de Santa Catarina. Cadernos de Agroecologia, v.8, n.2, p.1-5, nov. 2013. Disponível em: <http://www.aba-agroecologia.org.br/revistas/ index.php/cad/article/view/13933>. Acesso em: 03 abr. 2014.

GIL, Antonio Carlos. Métodos e técnicas de pesquisa social. 6 ed. São Paulo: Atlas, 2011.

GLIESSMAN, Stephen. Agroecología y agroecossistemas. Ciência \& Ambiente, n.27, p.107-120, jul./dez. 2003.

GOMES, Anna Carolina Porto; SILVA, Flávia Janaina de Araújo; PINTO, Márcia Eugênia de Souza. Apicultura e meliponicultura sustentável como instrumento e ressocialização de jovens do Centro de Apoio à Reabilitação - CARE em Campina Grande/PB. Cadernos de Agroecologia, v.8, n.2, p.1-4, nov. 2013. Disponível em: $<$ http://www.aba-agroecologia.org.br/revistas/index.php/cad/article/view/14220>. Acesso em: 03 abr. 2014.

GROPPO, Luís Antonio. A juventude como categoria social. In: GROPPO, Luís Antonio. Juventude: ensaios sobre Sociologia e História das Juventudes Modernas. Rio de Janeiro: DIFEL, 2000. (Coleção Enfoques. Sociologia) p. $7-27$

GUZMÁN, Eduardo Sevilla. Uma estratégia de sustentabilidade a partir da agroecologia. Agroec. e Desenv. Rur. Sustent., Porto Alegre, v.2, n.1, jan./mar. 2001. Disponível em: $<$ http://www.projetovidanocampo.com. br/agroecologia/uma estrategia de sustentabilidade a partir da agroecologia.pdf $>$. Acesso em: 21 maio 2014.

INSTITUTO BRASILEIRO DE GEOGRAFIA E ESTATÍSTICA. Censo Agropecuário 2006: agricultura familiar; primeiros resultados; Brasil, grandes regiões e unidades da federação. Brasília/Rio de Janeiro: MDA/ MPOG, 2009. Disponível em: <http://www.ibge.gov.br/home/estatistica/economia/agropecuaria/censoagro/ 
agri_familiar_2006/familia_censoagro2006.pdf>. Acesso em: 20 maio 2014.

MENDES, Diemesson San Tiago et al.. I etapa do projeto "formação de jovens agentes do desenvolvimento sustentável nas comunidades rurais do pentáurea, norte de Minas Gerais", projeto intervivência. Cadernos de Agroecologia, v.6, n.2, p.1-6, dez. 2011. Disponível em: <http://www.abaagroecologia.org.br/revistas/index.php/cad/article/view/10584>. Acesso em: 03 abr. 2014.

NUNES DA SILVA, José. Formação de jovens agentes de assistência técnica e extensão rural na perspectiva agroecológica: uma experiência no estado de Pernambuco - Brasil. Cadernos de Agroecologia, v.6, n.2, p.1-3, dez.2011. Disponível em: <http://www.aba-agroecologia.org.br/ revistas/index.php/cad/article/view/12217>. Acesso em: 03 abr. 2014.

OLIVEIRA, Daniela; SCHNEIDER, Sérgio. O futuro das unidades familiares: uma análise das possibilidades de sucessão hereditária entre os agricultores ecologistas de Ipê/RS. Rev. Bras. de Agroecologia, v.4, n.2, p.1293-1297, nov.2009. Disponível em: < file:///D:/Arquivos Cliente/ Downloads/8214-33811-1-PB.pdf>. Acesso em: 03 abr. 2014.

OLIVEIRA, Ladja Naftaly Rodrigues de et al.. Uso e potencialidades das forrageiras nativas: avanços para a formação de jovens agricultores na região semiárida paraibana. Cadernos de Agroecologia, v.6, n.2, p.1-4, dez. 2011. Disponível em: <http://www.aba-agroecologia.org.br/revistas/index.php/cad/ article/view/11750>. Acesso em: 03 abr. 2014.

PASQUALOTTO, Naiara et al.. A sucessão familiar em agroecossistemas hortícolas com base de produção na Agroecologia e na agricultura familiar na microrregião de Pato Branco-PR. Cadernos de Agroecologia, v.6, n.2, p.1-4, dez.2011. Disponível em: < http://www.aba-agroecologia.org.br/ revistas/index.php/cad/article/view/12137>. Acesso em: 03 abr. 2014.

PASQUALOTTO, Naiara; GODOY, Wilson Itamar; VERONA, Luiz Augusto Ferreira. Agricultura familiar e agroecologia: um olhar sobre o caminhar da juventude rural no sudoeste paranaense. Rev. Bras. de Agroecologia, v.8, n.3, p.72-79, 2013. Disponível em: < http://www.aba-agroecologia.org.br/ revistas/index.php/rbagroecologia/article/view/13199>. Acesso em: 03 abr. 2014.

RAMOS, Soraia de Fátima. Produtos agroecológicos e segurança alimentar e nutricional: ecoprofissionalização de jovens em Parelheiros, São Paulo. Cadernos de Agroecologia, v.8, n.2, p.14, nov. 2013. Disponível em: <http://www.aba-agroecologia.org.br/revistas/index.php/cad/article/ view/14939>. Acesso em: 03 abr. 2014.

REDIN, Ezequiel. O jovem rural conquistando o seu espaço: um [re]olhar sobre as questões sociais. Rev. Bras. de Agroecologia, v.4, n.2, p.3768-3771, nov. 2009. Disponível em: < http://www.abaagroecologia.org.br/revistas/index.php/cad/article/view/4877>. Acesso em: 03 abr. 2014.

SANTANA, Danielle Marcos et al.. Uma experiência de formação de jovens camponeses(as) em manejo ecológico de pragas de plantas alimentícias. Rev. Bras. de Agroecologia, v.4, n.2, p.3490-3493, nov. 2009. Disponível em: <http://www.aba-agroecologia.org.br/revistas/index.php/rbagroecologia/ article/viewFile/9123/6371>. Acesso em: 03 abr. 2014.

SILVA, Patrícia Sedrez da Rosa et al.. Coletivo Jovem de Meio Ambiente: vivenciando as questões sócio-ambientais na comunidade escolar. Rev. Bras. de Agroecologia, v.4, n.2, p.2703-2706, nov.2009. Disponível em: <http://www.aba-agroecologia.org.br/revistas/index.php/cad/article/view/4389>. Acesso em: 03 abr. 2014.

SILVA, Iranilde de Oliveira et al.. Jovens rurais, urbanos e quilombolas protagonizando o fortalecimento da agricultura familiar e a construção do conhecimento agroecológico no Estado do Rio de Janeiro. Cadernos de Agroecologia, v.5, n.1, p.1-5, 2010. Disponível em: <http://www.aba-agroecologia.org. br/revistas/index.php/cad/article/view/10115 > . Acesso em: 03 abr. 2014. 
TRICHES, Rozane Marcia et al.. Agroecologia e saúde sob o olhar dos jovens do meio rural ingressantes na Universidade Federal da Fronteira Sul no ano e 2012 - Campus Realeza/PR. Cadernos de Agroecologia, v.8, n.2, p.1-5, nov.2013. Disponível em: < http://www.aba-agroecologia.org.br/ revistas/index.php/cad/article/view/15103>. Acesso em: 03 abr. 2014.

TROIAN, Alessandra; DAL SOGLIO, Fábio Kesseler. Jovens rurais entre a diversificação e o monocultivo: o caso dos produtores de tabaco de Arroio do Tigre/RS. Cadernos de Agroecologia, v.8, n.2, p.1-5, 2013. Disponível: <http://www.aba-agroecologia.org.br/revistas/index.php/cad/article/ view/13495>. Acesso em: 03 abr. 2014.

URTEAGA, Maritza. La construcción juvenil de la realidad: jóvenes mexicanos contemporáneos. México: Universidad Autónoma Metropolitana, 2011.

WEISHEIMER, Nilson. Juventudes rurais: mapa de estudos recentes. Brasília: Ministério do Desenvolvimento Agrário, 2005. 